\title{
Epidemiology of SARS-CoV-2 and Emergence of UK Variant in Zintan City of Libya
}

\author{
Abdulwahab Kammon 1,2*, Abdulhmid Giweli1,3, Esadk Erhouma',3, Elhadi Rammah', \\ Ashour Elusta'2, Salem Knifo², Walid Ali², Walid Benbubaker4, Fawzi Ebrahim', Ali Elarabi2,3 \\ ${ }^{1}$ National Research Center for Tropical and Transboundary Diseases, Zintan, Libya \\ ${ }^{2}$ Biotechnology Research Center-Zintan Branch, Zintan, Libya \\ ${ }^{3}$ Faculty of Science, Alzintan University, Zintan, Libya \\ ${ }^{4}$ Libyan Authority for Scientific Research, Tripoli, Libya \\ ${ }^{5}$ Biotechnology Research Center, Tripoli, Libya \\ Email: *a.kammon@uot.edu.ly
}

How to cite this paper: Kammon, A., Giweli, A., Erhouma, E., Rammah, E., Elusta, A. Knifo, S., Ali, W., Benbubaker, W., Ebrahim, F. and Elarabi, A. (2021) Epidemiology of SARS-CoV-2 and Emergence of UK Variant in Zintan City of Libya. Open Journal of Epidemiology, 11, 349-359. https://doi.org/10.4236/ojepi.2021.114029

Received: August 8, 2021

Accepted: October 8, 2021

Published: October 11, 2021

Copyright (C) 2021 by author(s) and Scientific Research Publishing Inc. This work is licensed under the Creative Commons Attribution International License (CC BY 4.0).

http://creativecommons.org/licenses/by/4.0/

\begin{abstract}
Introduction: Coronavirus Disease 2019 (COVID-19) is an infectious respiratory disease caused by SARS-CoV-2. The disease was first broke out in Wuhan City, Hubei Province, China and subsequently spread to all countries and was considered by WHO as a worldwide pandemic. This study is aimed to determine the epidemiology of SARS-CoV-2 and the presence of UK variants in Zintan city of Libya taking some risk factors into account. Methods: In a cross-sectional retrospective study, a total of 15486 nasopharyngeal swabs were collected from COVID-19 suspected patients, travelers and people need disease-free certificates for hospital admission, etc. The samples were collected during the period from August 2020 to June 2021 and tested using real-time RT-PCR (rRT-PCR) kits for SARS-CoV-2 and UK variants. Age groups, sex, and monthly weather were considered as risk factors. Results: The positivity rate of COVID-19 in Zintan city was estimated to be $(3891 ; 25.12 \%)$ for the period from August 2020 to June 2021. Females showed significantly $(\mathrm{p}<0.05)$ higher positivity rate $(2100 ; 54 \%)$ as compared to males $(1791 ; 46 \%)$. Out of the 3891 positive cases, 52 were deceased. The Case Fatality Rate (CFR) was 1.33 recorded significantly in cases aged $\geq 65$ years which was higher in males $(56.66 \%)$ than females $(43.33 \%)$. The peak of the first wave of infection was recorded in October 2020 (590; $15.15 \%)$ whereas the peak of the second wave of infection was recorded in April 2021 (727; 18.71\%). The positivity rate was decreased as the temperature increased. UK variant is detected firstly in May 2021 with the percentage of $6.2 \%$ of tested samples. Conclusions: Health Authorities are encouraged to continue implementing the control measures during the de-
\end{abstract}


crease phase of infection to stop transmission of the virus in the next wave.

Early detection of new variants and studying their genetic characteristics play a valuable role in prevention and control.

\section{Keywords}

SARS-CoV-2, UK Variant, Epidemiology, Zintan, Libya, rRT-PCR

\section{Introduction}

COVID-19 is an acute severe respiratory disease caused by SARS-CoV-2 belonging to the genus betacoronavirus of the family coronaviridae. The disease was first broke out in Wuhan City, Hubei Province, China and subsequently spread to all countries and was considered by $\mathrm{WHO}$ as a worldwide pandemic [1]. More than one year of its appearance, the pandemic is still out of control leading to a severe impact on people's health, social life, economy and education. The first case of COVID-19 in Libya was recorded on 24/3/2020, then the cases began to increase exponentially, especially after the return of people stranded abroad. However, in Zintan city cases with antibodies to SARS-CoV-2 were recorded on April 2020 by rapid test [2].

Coronaviruses are vulnerable to spontaneous mutations leading to the emergence of new variants. Most of the variants of concern contain mutations in the Receptor-Binding Domain (RBD) of the spike protein. It seems these mutations are responsible for increased viral infectivity, virulence, and immune evasion potency.

The United Kingdom (UK) has detected a new variant of SARS-CoV-2 from samples initially taken in Kent on September 20th and London on September $21^{\text {st }}, 2020$, which was found associated with increased spread [3]. The spreading rate of UK variants could be greater than $70 \%$ of cases compared to the normal SARS-CoV-2 virus, with an $\mathrm{R}$ index growth of 0.4 [4]. This variant, called VOC202012/01 (B.1.1.7) is defined by multiple spike protein changes (deletion 69-70, deletion 144, amino acid change N501Y, A570D, D614G, P681H, T716I, S982A, $\mathrm{D} 1118 \mathrm{H})$ as well as by mutations in other genomic regions [5]. The deletion at positions 69 and 70 evolved spontaneously in other SARS-CoV-2 variants and is hypothesized to increase transmissibility and the potential to enhance the ability of SARS-CoV-2 to generate vaccine escape variants that would have otherwise significantly reduced viral fitness [6].

There is a lack of information about the epidemiological situation and emergence of SARS-CoV-2 variants in Zintan city. It is very important to determine a detailed epidemiological profile in order to implement the appropriate intervention strategies. Therefore, this study is conducted to determine the positivity rate of SARS-CoV-2 and the presence of UK variant using rRT-PCR taking some risk factors into account. 


\section{Materials and Methods}

\subsection{Sampling}

This cross sectional retrospective study was conducted to determine the percentage of positive cases of COVID-19 in Zintan city of Libya. A total of 15,486 nasopharyngeal swabs were collected from suspected patients, travelers, people need disease free certificate for hospital admission, etc. The samples were collected during the period from August 2020 to June 2021 including 7110 (45.9\%) and 8376 (54.1\%) from females and males, respectively. The samples were analyzed by multiplex rRT-PCR assay at the PCR Laboratory of Biotechnology Research Center, Zintan Branch. To determine the presence of UK variant of SARS$\mathrm{CoV}-2$, a total of 405 positive samples were randomly selected and tested.

\subsection{RNA Extraction}

RNA was extracted from nasopharyngeal swabs using alphaPrep ${ }^{\text {Tm }}$ Viral DNA/RNA extraction kit (AlphaGene, Korea). The samples were prepared as per the manufacturer's instructions and the extraction was completed by automated NC-15 PLUS instrument (HanwoolTPC, Korea).

\subsection{Real Time RT-PCR Assay}

\subsubsection{Detection of SARS-CoV-2}

In this study, rRT-PCR commercial kit was used for the qualitative detection of SARS-CoV-2 nucleoprotein gene $(\mathrm{N})$ and human housekeeping (RNAse $\mathrm{P}$ ) gene as an Internal Control (IC) (Bio-Speedy ${ }^{\circledR}$, Turkey). The reaction and program were conducted as per the manufacturer's instructions using MIC-PCR device (Biomolecular systems, Australia). Samples with quantitation cycle $(\mathrm{Cq}) \leq 33$ was considered positive for COVID-19.

\subsubsection{Detection of SARS-CoV-2 UK Variant}

SARS-CoV-2 previous positive samples were chosen randomly and tested for the presence of UK variant based on the HV 69/70 deletion of the S gene for SARSCoV-2 in respiratory samples using rRT-PCR commercial kit (Vitassay qPCR, Spain). The assay allows the detection of SARS-CoV-2 and the HV 69/70 deletion of the $S$ gene for SARS-CoV-2 associated to the SARS-CoV-2 VOC-202012/01 (lineage B.1.1.7) variant and other variants by real-time RT-PCR in nasopharyngeal swabs. The assay is targeting a conserved region of the $\mathrm{S}$ gene for SARS-CoV-2 HV 69/70 deletion, a conserved region of the ORF1ab and N genes for SARS-CoV-2 and human housekeeping (RNAse P) gene as an Internal Control (IC). The reaction setup steps were followed as per the manufacturer's instructions using 96-wells rRT-PCR device (Azure Biosystems, USA). Samples with quantitation cycle $(\mathrm{Cq}) \leq 35$ was considered positive for UK variant.

\subsection{Risk Factors}

Age groups, sex and monthly weather were considered as risk factors in the cur- 
rent study. The averages of monthly temperature were obtained from the website: https://weatherspark.com/y/71722/Average-Weather-in-Zintan-Libya-Year-Rou nd.

\subsection{Statistical Analysis}

Data obtained were subjected to statistical analyses using SPSS 26 computer program (SPSS Inc. Chicago, Illion, USA). A descriptive analysis measuring frequency and percent was used. Chi-square test was also used to determine the level of association among sex, age group, temperature and period at the significance level of $\mathrm{p}<0.05$.

\section{Results}

Out of 15,486 samples tested, 3891 (25.12\%) were positive and 10,970 (70.8\%) were negative for COVID-19. However, 409 (2.6\%) samples were negative for internal control and 216 samples (1.4\%) were in the criteria of re-testing. The number of negative samples for internal control and retested samples showed monthly gradual decrease (Table 1 and Figure 1).

Table 1. Total number of positive, negative, re-swabbed and re-tested samples.

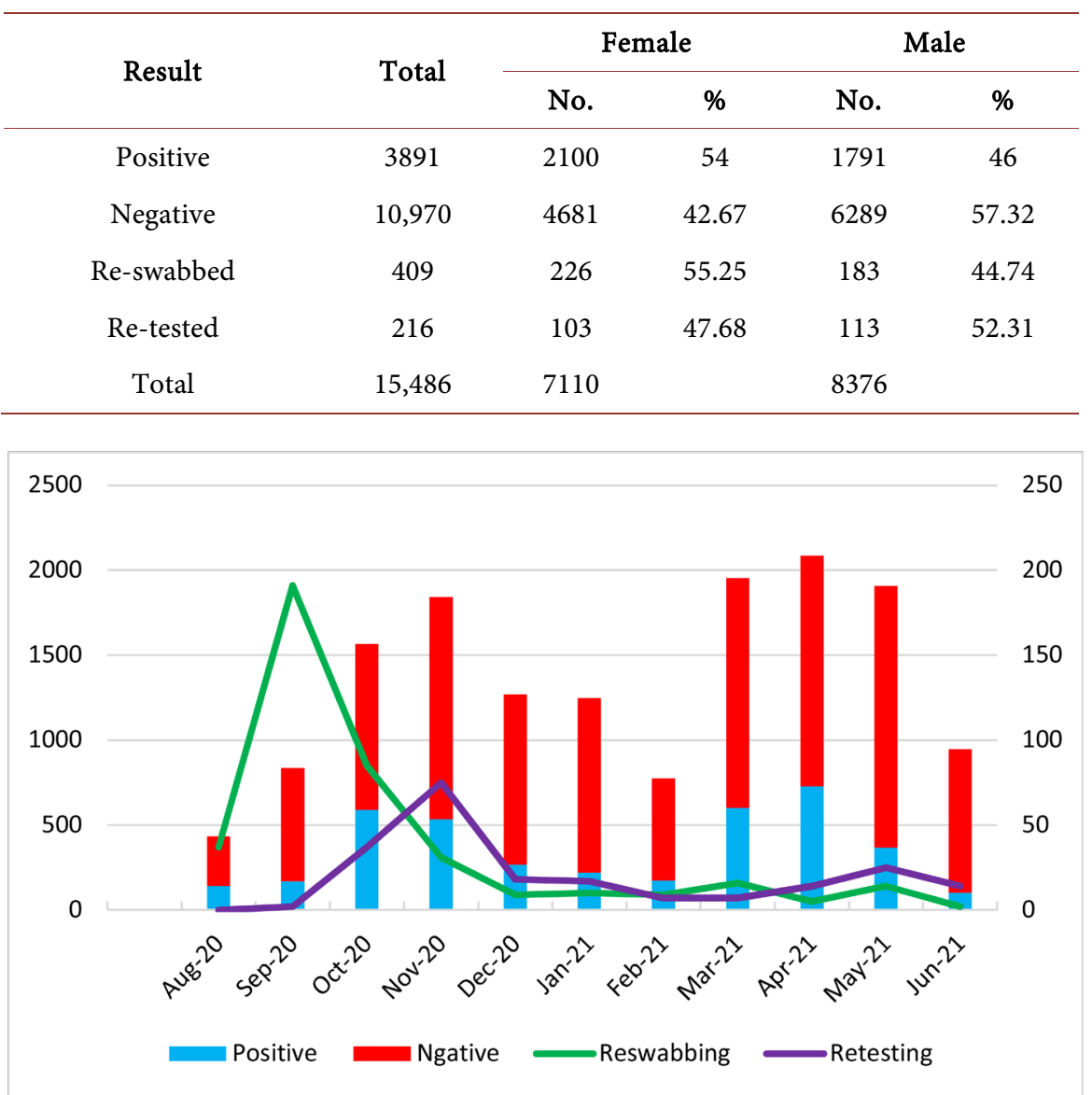

Figure 1. Total number of positive and negative cases/month and percentage of re-swabbed and re-tested samples. 
Females showed significantly $(\mathrm{p}<0.05)$ higher positive rate for COVID-19 $(2100 ; 54 \%)$ as compared to the positive rate $(1791 ; 46 \%)$ in males (Table 1$)$. Differences among age groups were also significant at $\mathrm{p}<0.05$, while the highest positive rate was recorded in patients aged 25 - 34 years old $(706 ; 18.15 \%)$ which was higher in females $(406 ; 57.5 \%)$ than in males $(300 ; 42.5 \%)$ (Table 2).

Out of the 3891 positive cases, 52 were deceased (Table 3). The Case Fatality Rate (CFR) in Zintan city from August 2020 to June 2021 was 1.33 . The highest percentage of deaths (57.7\%) was recorded in cases aged $\geq 65$ years which was higher in males $(56.66 \%)$ than females $(43.33 \%)$. However, there were no deaths in the group aged $\leq 24$ years old (Table 3 ).

In the year 2020, the highest positivity rate was recorded in October (590; $15.15 \%)$ which was higher in females $(329 ; 55.76 \%)$ compared to males (261; 44.24\%) (Table 4 and Figure 2). This might be considered the peak of the first

Table 2. Number and percentage of positive samples among females and males in different age groups.

\begin{tabular}{ccccccc}
\hline \multirow{2}{*}{ Age group } & \multicolumn{2}{c}{ Total } & \multicolumn{2}{c}{ Female } & \multicolumn{2}{c}{ Male } \\
\cline { 2 - 7 } & No. & $\%$ & No. & $\%$ & No. & $\%$ \\
\hline$\leq 14$ & 162 & 4.16 & 83 & 51.2 & 79 & 48.8 \\
$15-24$ & 557 & 14.31 & 307 & 55.1 & 250 & 44.9 \\
$25-34$ & 706 & 18.15 & 406 & 57.5 & 300 & 42.5 \\
$35-44$ & 705 & 18.11 & 384 & 54.5 & 321 & 45.5 \\
$45-54$ & 628 & 16.13 & 328 & 52.2 & 300 & 47.8 \\
$55-64$ & 448 & 11.51 & 233 & 52 & 215 & 48 \\
$\geq 65$ & 419 & 10.80 & 223 & 53.2 & 196 & 46.8 \\
Missing age & 266 & 6.83 & 136 & 51.1 & 130 & 48.9 \\
Total & 3891 & 100 & 2100 & 54 & 1791 & 46 \\
\hline
\end{tabular}

Table 3. Number and percentage of deaths among females and males in different age groups.

\begin{tabular}{ccccc}
\hline Age group & Total & Female & Male & $\%$ \\
\hline$\leq 14$ & 0 & 0 & 0 & 0 \\
$15-24$ & 0 & 0 & 0 & 0 \\
$25-34$ & 2 & 2 & 0 & 3.84 \\
$35-44$ & 2 & 1 & 1 & 3.84 \\
$45-54$ & 5 & 1 & 4 & 9.61 \\
$55-64$ & 6 & 0 & 6 & 11.53 \\
$\geq 65$ & 30 & 13 & 17 & 57.7 \\
Missing age & 7 & 2 & 5 & 13.46 \\
Total & 52 & 19 & 33 & 100 \\
\hline
\end{tabular}


Table 4. Number and percentage of positive samples among females and males and temperature in the period from August 2020 to June 2021.

\begin{tabular}{cccccccc}
\hline \multirow{2}{*}{ Months } & $\begin{array}{c}\text { Temperature } \\
\left({ }^{\circ} \mathrm{C}\right)^{*}\end{array}$ & \multicolumn{2}{c}{ Total } & \multicolumn{2}{c}{ Female } & \multicolumn{2}{c}{ Male } \\
\cline { 3 - 7 } & 34 & 141 & 3.63 & 83 & 58.86 & 58 & 41.13 \\
\hline Aug 2020 & 32 & 168 & 4.32 & 89 & 52.97 & 79 & 47.02 \\
Sep 2020 & 26 & 590 & 15.15 & 329 & 55.76 & 261 & 44.24 \\
Oct 2020 & 23 & 533 & 13.63 & 313 & 58.72 & 220 & 41.27 \\
Nov 2020 & 18 & 269 & 6.91 & 129 & 48.13 & 140 & 52.23 \\
Dec 2020 & 14 & 220 & 5.65 & 112 & 50.91 & 108 & 49.09 \\
Jan 2021 & 16 & 173 & 4.45 & 84 & 48.55 & 89 & 51.44 \\
Feb 2021 & 20 & 601 & 15.44 & 316 & 52.57 & 285 & 47.42 \\
Mar 2021 & 33 & 727 & 18.71 & 381 & 52.41 & 346 & 47.59 \\
Apr 2021 & 36 & 368 & 9.46 & 206 & 55.97 & 162 & 44.02 \\
May 2021 & 36 & 101 & 2.65 & 58 & 57.42 & 43 & 42.57 \\
Jun 2021 & 40 & 3891 & 100 & 2100 & 53.97 & 1791 & 46.02 \\
\hline Total & & & & & & &
\end{tabular}

*Average of monthly temperature from August 2020 to June 2021.

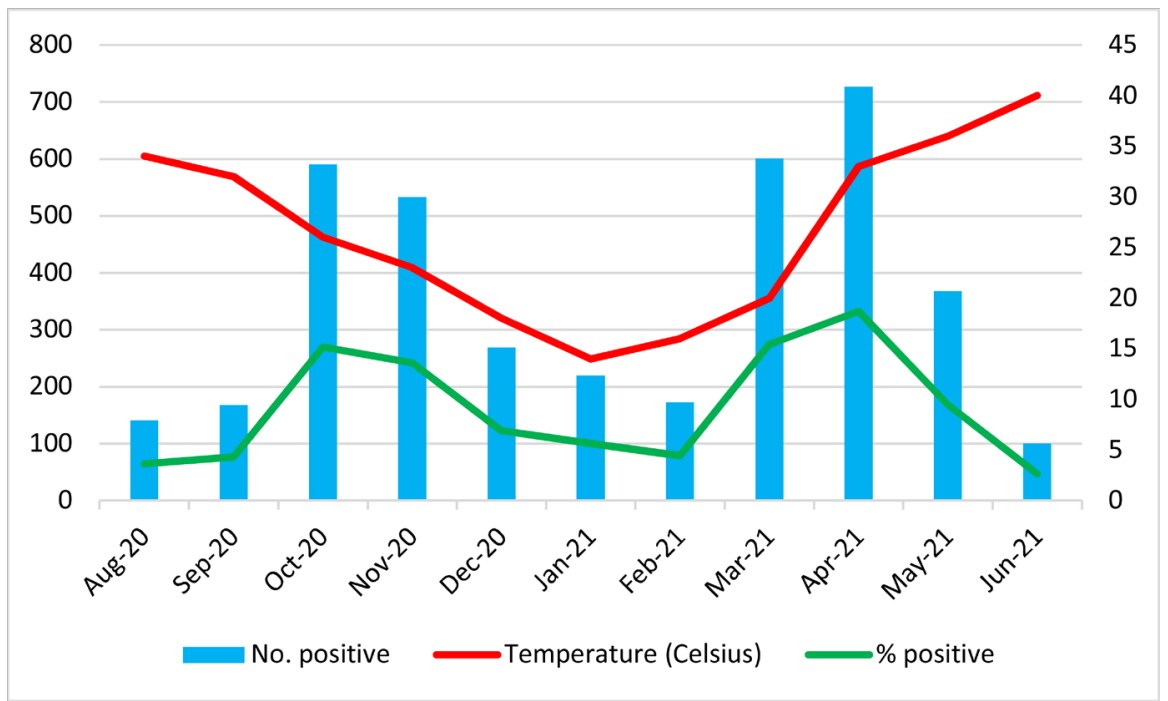

Figure 2. Number and percentage of positive cases in different months and monthly temperature.

wave of infection. The positive cases begin to decrease gradually until February 2021 when the lowest rate was recorded (173; 4.45\%). One month later (i.e. March 2021), the rate begin to increase until April when the highest rate reached 727 cases $(18.71 \%)$ which was again higher in females $(381 ; 52.41 \%)$ than in males $(346 ; 47.59 \%)$ and then decreased gradually. This might be considered the peak of the second wave of infection. The positivity rate was also compared to the average of temperature of every month. The number of the positive cases was 
decreased as the temperature increased and vice versa (Table 4 and Figure 2).

Out of the 405 samples examined for the UK variant, 25 samples (6.2\%) were positive. The first positive sample was recorded on 16/5/2021. All positive samples were found in May and June 2021. Males showed higher (16;64\%) positive rate for UK variant compared to females $(9 ; 36 \%)$.

\section{Discussion}

The positivity rate of SARS-CoV-2 identified in Zintan city was $25.2 \%$. There is lack in published information about the positivity rates of COVID-19 in Libya especially at regional level, except the weekly report (Libya COVID-19 Surveillance Weekly Bulletin) issued by WHO. In Misrata, a city of Libya, representative samples of 897 participants were tested for SARS-COV-2 IgM/IgG antibodies. 30 participants were positive for IgM or IgG indicating a prevalence of $3.4 \%$ [7].

In the current study, 409 (2.6\%) samples were negative for internal control which may indicate improper swabbing and 216 samples (1.4\%) were in the criteria of re-testing as per the kit manufacturers' instructions. At the beginning of the pandemic, there was lack of the persons who trained previously for monitoring, investigation and sampling. Therefore, some volunteers were trained on sampling and donning and doffing of Personal Protection Equipment (PPE) to support the main team. Lately, the number of negative samples for internal control and retested samples showed monthly gradual decrease. This may explain enhancement in experience of sampling as well as PCR procedure.

In our study, females showed higher positive rate for COVID-19 (2100; 54\%) as compared to the positive rate $(1791 ; 46 \%)$ in males. This result is in agreement with our previous serological work included 219 samples collected from public community and health care workers in Zintan City. Out of the 219 samples tested, $6(2.74 \%)$ samples were seropositive for SARS-CoV-2 and all of them were females [2]. Our findings were in contrast to the cross sectional study recently conducted to determine the prevalence of COVID-19 in Tarhouna city of Libya. Out of 540 cases, the infection rate was estimated to be $70.74 \%$ and $29.50 \%$ in males and females respectively [8]. It was also in contrast to the study included some regions of Ghana in which males were mostly infected (4897; 51.5\%) compared to females. Individuals between the ages 21 - 30 years recorded the highest number of infections $(3144,33.4 \%)$ with significant association between gender or age and infection with SARSCoV-2 $(\mathrm{p}<0.05)$ [9].

Among age groups, the highest positive rate was recorded in patients aged 25 34 years old $(706 ; 18.15 \%)$ which was higher in females $(406 ; 57.5 \%)$ than in males $(300 ; 42.5 \%)$. Individuals between the ages 21 - 30 years recorded the highest number of infections (3144; 33.4\%). There was significant association between gender or age and infection with SARS-CoV-2 $(\mathrm{p}<0.05)$ [9].

Out of the 3891 positive cases, 52 were deceased. The case fatality rate (CFR) in Zintan city from August 2020 to June 2021 was 1.33 . The highest percentage 
of deaths $(57.7 \%)$ was recorded in cases aged $\geq 65$ years which was higher in males $(56.66 \%)$ than females (43.33\%). However, there were no deaths in the group aged $\leq 24$ years old. This result is in agreement to the findings of Mahmoud et al. [10] who estimated the fatality ratio to be 1.40 in Libya in a particular period of time. Shi et al. [11] in China reported the risk factors for death were older age, male, severe or critical cases. In Ecuador, Ortiz-Prado et al. [12] found the presence of comorbidities, being male and older than 65 years were important determinants of mortality. Within Italy, COVID-19 deaths are mainly observed among older, male patients who also have multiple comorbidities [13].

In the year 2020, the highest positivity rate was recorded in October (590; $15.15 \%)$ which was higher in females $(329 ; 55.76 \%)$ compare to males $(261 ; 44.24 \%)$. This might be considered the peak of the first wave of infection. The positive cases begin to decrease gradually until February, 2021 when the lowest rate was recorded (173; 4.45\%). One month later (i.e. March 2021), the rate begin to increase until April when the highest rate reached 727 cases (18.71\%) which was again higher in females $(381 ; 52.41 \%)$ than in males $(346 ; 47.59 \%)$ and then decreased gradually. This might be considered the peak of the second wave of infection.

The effect of climate on COVID-19 is contradictory. In our study, the positivity rate was compared to the average of temperature for every month from $\mathrm{Au}$ gust 2020 to June 2021. The number of the positive cases was decreased as the temperature increased and vice versa. This result is in agreement with Simiao et al. [14] who reported that countries are expected to see a decline in new COVID-19 cases during summer and resurgence during winter. The higher temperatures and more intense UV radiation in summer are likely to support public health measures to contain SARS-CoV-2. In contrast, Bukhari et al. [15] reported that cases in warm and humid countries have consistently increased, accounting for approximately 500,000 cases in regions with absolute humidity $>9 \mathrm{~g} / \mathrm{m}^{3}$, therefore effective public health interventions must be implemented to stop the spread of COVID-19. This also means that summer season would not alone stop the spread of COVID-19 in any part of the world. Moreover, Dimitrios et al. [16] concluded that in the absence of public health measures high temperatures cannot probably mitigate outbreaks. However, we also noted sudden increase of the cases in July 2021 (data not included) although the temperature still high which we believe is the beginning of third wave of infection thus supporting the findings of Bukhari et al. [15] and Dimitrios et al. [16].

Out of the 405 samples examined for the UK variant, 25 samples (6.2\%) were positive. The first positive sample for UK variant in Zintan city was recorded on 16/5/2021. All positive samples were found in May and June 2021. Males showed higher $(16 ; 64 \%)$ positive rate for UK variant compared to females $(9 ; 36 \%)$. This variant was first reported in UK in September, 2020 [17] [18]. Kemp et al. [6] reported recurrent emergence and significant onward transmission of a six-nucleotide deletion in the S gene, which results in loss of two amino acids: H69 and 
V70. More than $98 \%$ of positive SARSCoV-2 infections in England are due to Variant of Concern (VOC) 202012/01 (lineage B.1.1.7), and the spread of this new variant has led to a surge in COVID-19 cases and deaths [18]. However, in our study we noticed decrease in COVID-19 positive rate from $18.71 \%, 9.46 \%$, and $2.65 \%$ in April, May and June 2021, respectively although UK variant detected only in May and June. The diagnosis of COVID-19 is continuing daily in our PCR lab. After analysis of data of our study and while writing up this manuscript we found sudden increase in the positive cases in the month of July, 2021 which was not included in this study. Therefore, we decided to examine some positive samples for the UK variant. The result revealed 5 (17.3\%) positive samples out of 29. No more positive samples were detected beyond 17/7/2021 thus we believe the UK variant is not the cause of the third wave of infection but more aggressive variant. However, it is not currently possible to check for other variants such as delta due to lack of specific diagnostic kit.

\section{Conclusion}

The outcome of this study indicates that the high case fatality rate in the age group of $\geq 65$ years needs more attention from health authorities. Climate does not affect the spread of the virus. UK variants of SARS-CoV-2 did not show a high level of transmission and the reason behind the decrease of its positive cases is not clear thus needs more investigation. Health authorities are encouraged to strengthen and continue implementing the control measures during the decrease phase of infection to stop transmission of the virus in the next wave. Early detection of new variants and studying their genetic characteristics play a valuable role in prevention and control.

\section{Authors' Contributions}

AK: Study design, rRT-PCR and writing; AG: Study design and rRT-PCR; EE and ER: rRT-PCR; AE and AE: RNA extraction; SK and WA: Data collection; WB: Data analysis with SPSS; FE: Logistic support; AIL: Review \& editing.

\section{Ethical Approval}

Ethical approval for this study was obtained from the Libyan National Committee for Biosafety and Biotechnology. Due to the retrospective nature of the study, informed permission was not obtained, and data were analyzed anonymously.

\section{Conflicts of Interest}

The authors declare no conflicts of interest regarding the publication of this paper.

\section{References}

[1] World Health Organization (2020) WHO Director-General's Opening Remarks at the Media Briefing on COVID-19-11 March 2020. 
https://www.who.int/director-general/speeches/detail/who-director-general-s-openi ng-remarks-at-the-media-briefing-on-covid-19---11-march-2020

[2] Kammon, A.M., El-Arabi, A.A., Erhouma, E.A., Mehemed, T.M. and Mohamed, O.A. (2020) Seroprevalence of Antibodies against SARS-CoV-2 among Public Community and Health-Care Workers in Alzintan City of Libya. medRxiv Preprint. https://doi.org/10.1101/2020.05.25.20109470

[3] Mahase, E. (2020) COVID-19: What Have We Learnt about the New Variant in the UK? British Medical Journal, 371, Article No. m4944. https://doi.org/10.1136/bmj.m4944

[4] Conti, P., Caraffa, A., Gallenga, C.E., Kritas, S.K., Frydas, I., Younes, A., Emidio, P.D., Tetè, G., Pregliasco, F. and Ronconi, G. (2021) The British Variant of the New Coronavirus-19 (Sars-Cov-2) Should Not Create a Vaccine Problem. Journal of Biological Regulators \& Homeostatic Agents, 35, 1-4.

[5] Harvey, W.T., Carabelli, A.M., Jackson, B., Gupta, R.K., Thomson, E.C., Harrison, E.M., et al. (2021) SARS-CoV-2 Variants, Spike Mutations and Immune Escape. Nature Reviews Microbiology, 19, 409-424. https://doi.org/10.1038/s41579-021-00573-0

[6] Kemp, S.A., Harvey, W.T., Datir, R.P., Collier, D.A., Ferreira, I.A.T.M., Carabelli, A.M., Robertson, D.L. and Gupta, R.K. (2020) Recurrent Emergence and Transmission of a SARS-CoV-2 Spike Deletion H69/V70. Social Science Research Network. https://doi.org/10.2139/ssrn.3780277

[7] Zarmouh, A., Elaswdi, H., Elakhtel, E., Abufalgha, K. and Taraina, M. (2021) Epidemiology of COVID-19 in Misrata, Libya: A Population-Based Surveillance Study. Open Journal of Epidemiology, 11, 101-112. https://doi.org/10.4236/ojepi.2021.111010

[8] Hanan, M.M., Abdulsalam, S.M., Abdulati, E.S., Khaled, A.A., Ashraf, A.N., Abdulaziz, M.A. and Mahmud, E.A. (2021) Preliminary Epidemiological Investigation of SARS-CoV-2 and Risk Factors Associated with Infection in Tarhouna, Libya. Fortune Journal of Health Sciences, 4, 373-382.

[9] Owusu, M., Sylverken, A.A., Ankrah, S.T., El-Duah, P., Ayisi-Boateng, N.K., Yeboah, R., et al. (2020) Epidemiological Profile of SARS-CoV-2 among Selected Regions in Ghana: A Cross-Sectional Retrospective Study. PLoS ONE, 15, Article ID: e0243711. https://doi.org/10.1371/journal.pone.0243711

[10] Mahmoud, A.S., Dayhum, A.S., Rayes, A.A., Annajar, B.B. and Eldaghayes, I.M. (2021) Exploiting Epidemiological Data to Understand the Epidemiology and Factors That Influence COVID-19 Pandemic in Libya. World Journal of Virology, 10, 156-167. https://doi.org/10.5501/wjv.v10.i4.156

[11] Shi, F., Wen, H., Liu, R., Bai, J., Wang, F., Mubarik, S., Liu, X., Yu, Y., Hong, Q., Cao, J. and Yu, C. (2021) The Comparison of Epidemiological Characteristics between Confirmed and Clinically Diagnosed Cases with COVID-19 during the Early Epidemic in Wuhan, China. Global Health Research Policy, 6, Article No. 18. https://doi.org/10.1186/s41256-021-00200-8

[12] Ortiz-Prado, E., Simbaña-Rivera, K., Barreno, L.G., Diaz, A.M., Barreto, A., Moyano, C., et al. (2021) Epidemiological, Socio-Demographic and Clinical Features of the Early Phase of the COVID-19 Epidemic in Ecuador. PLoS Neglected Tropical Diseases, 15, Article ID: e0008958. https://doi.org/10.1371/journal.pntd.0008958

[13] Onder, G., Rezza, G. and Brusaferro, S. (2020) Case-Fatality Rate and Characteristics of Patients Dying in Relation to COVID-19 in Italy. Journal of the American Medical Association, 323, 1775-1776. https://doi.org/10.1001/jama.2020.4683 
[14] Simiao, C., Klaus, P., Michael, K., Pascal, G., Chen, W., Till, B. and David, E.B. (2021) Climate and the Spread of COVID-19. Scientific Reports, 11, Article No. 9042. https://doi.org/10.1038/s41598-021-87692-Z

[15] Bukhari, Q., Massaro, J.M., D’Agostino, R.B. and Khan, S. (2020) Effects of Weather on Coronavirus Pandemic. International Journal of Environmental Research and Public Health, 17, Article No. 5399. https://doi.org/10.3390/ijerph17155399

[16] Dimitrios, P., Evangelia, G.K., Nikiforos, A., Nikolaos, S.T., Constantinos, C., Sotirios, T. and Meletios, A.D. (2021) A Review of the Impact of Weather and Climate Variables to COVID-19: In the Absence of Public Health Measures High Temperatures Cannot Probably Mitigate Outbreaks. Science of the Total Environment, 768, Article ID: 144578. https://doi.org/10.1016/j.scitotenv.2020.144578

[17] Wise, J. (2020) COVID-19: New Coronavirus Variant Is Identified in UK. British Medical Journal, 371, Article No. m4857. https://doi.org/10.1136/bmj.m4857

[18] Davies, N.G., Abbott, S., Barnard, R.C., Jarvis, C.I., Kucharski, A.J., Munday, J.D., et al. (2021) Estimated Transmissibility and Impact of SARS-CoV-2 lineage B.1.1.7 in England. Science, 372, Article No. eabg3055.

https://doi.org/10.1126/science.abg3055 